\title{
ENTREVISTA COM WARREN DEAN ${ }^{\circ}$
}

\author{
Concedida a Maria Luisa Nabinger de Almeida \\ Departamento de Sociologia e Antropologia da UFMA
}

MARIA LUISA - A primeira questāo refere-se ao tema do curso de pós-graduaçāo oferecido no Departamento de História da USP, no primeiro semestre de 1985.

WARREN DEAN - O assunto do curso tratava da história do conscrvacionismo no Brasil, ou digamos, as tendências conservacionistas. O material teórico que tentei apresentar foi aquele elaborado, principalmente, pela Ciência Ecológica. Foi uma tentativa de confrontar a História, a Ecologia e a Ciência Política, pois vejo o movimento conservacionista como uma frente de todos os anseios ecológicos de qualquer sociedade. Isso nāo é novidade em outros países. Há, na Europa e nos Estados Unidos, vários historiadores que tentam focalizar os problemas ecológicos tanto em suas aulas de História quanto em seus trabalhos.

MARIA LUISA - A realizaçāo desse curso na USP refletiria uma consciência ecológica dos historiadores brasileiros?

\footnotetext{
- Entrevista publicada no jornal O Estado do Maranhão, 16 de outubro de 1994, p. 26
}

WARREN DEAN - Há fortes indícios, na sociedade brasileira, de que a problemática ecológica está bastante amadurecida. Muitas pessoas estão lutando em favor de uma tomada de consciência, da necessidade de medidas efetivas para proteger o meio ambiente. De certa forma, acho que os historiadores podem ajudar esses movimentos.

MARIA LUISA - O Sr. poderia mencionar alguns trabalhos de historiadores americanos que abordam a questão ecológica?

WARREN DEAN - Há, nos Estados Unidos, uma ampla bibliografia que, infelizmente, continuará inacessível por muito tempo. Em todo o caso, eu poderia mencionar alguns autores de livros recentes, muito comentados nos meios acadêmicos, como Alfred Crosby - O Intercâmbio Colombiano; Willian Cronon - Changes in the Land; Carl Sauer The Early Spanish Man.

Alfred Crosby, por exemplo, é um historiador de formação em biologia que enfatizou a problemática da transferência para a América, desde as primeiras viagens de Colombo, das concepçōes européias 
sobre a natureza. $O$ autor reúne dados já levantados por outros historiadores, mas apresenta uma visāo muito interessante da situaçăo histórica. Na transferência de plantas do Novo para o Velho Mundo, a oferta de alimentos, especialmente na Europa, ficou relativamente estável. Exatamente na época em que o capitalismo estava se desenvolvendo, entrando $\mathrm{em}$ uma fase importante, a agricultura acompanhou esta mudança e, de certa forma, estimulou-o, pois a entrada do milho, da batata e de outras plantas cultivadas fez com que o europeu ganhasse um regime agrícola muito estável e muito rico, que permitiu a continuidade do crescimento da população européia nos séculos seguintes. No entanto, no Novo Mundo, o impacto adquiriu uma forma devastadora: os micróbios, que tinham evoluído durante milhares de anos no lado dos europeus, dos africanes e dos asiáticos, eliminaram $90 \%$ a $95 \%$ da população com a chegada dos europeus nas Américas. Toda essa problemática é extremamente importante para a história do imperialismo e que nāo tem sido enfatizada suficientemente.

Outro livro de que gosto muito, escrito por William Cronon, fala sobre a história das florestas no nordeste dos Estados Unidos. O autor enfatiza as diferenças culturais, as atitudes dos europeus em contraste com as dos indigenas. Os documentos sāo realmente bastante ricos quanto à história dessa regiāo do país e mostram que os índios suportavam épocas de escassez de caça, pois se eles insistissem em comer todos os dias, a única saída seria matar um número de animais acima das possibilidades de renovação dos estoques. Daí, eles agüentarem a fome, apesar de correrem o risco de ter prejudicada a evoluçāo de suas capacidades mentais e morais. Trata-se de uma atitude que os europeus não chegaram a entender. Eles achavam que os índios eram defeituosos porque preferiam passar fome. O livro de Cronon está cheio de observaçōes extremamente interessantes, pois mostra a diferença entre a cultura dos indí- genas e a extrema agressividade dos curopeus quando tiveram a oportunidade de quebrar, de desfrutar ou mesmo de eliminar todo o ecossistema para o seu ganho imediato. Por outro lado, podemos observar um aspecto interessante nesse tipo de historiografia: ela apresenta um enfoque interdisciplinar, na qual os pesquisadores de outras áreas fazem comentários e trocam informaçōes $\mathbf{c}$ idéias. Esse procedimento encontramos, especialmente, entre geógrafos, antropólogos e economistas.

MARIA LUISA - A chegada do espanhol e do português na América Latina representou o início de uma cultura depredatória. Há, na historiografia latino-americana, estudos ou registros sobre esse tipo de colonizaçāo?

WARREN DEAN - As crônicas săo extremamente interessantes. Os primeiros cronistas da costa do Brasil, registraram as matérias-primas interessantes para o comércio de Portugal. Com isso, toda a natureza que deve ter sido uma coisa fascinante, extraordinária e muito rica, reduziu-se a uma lista limitada de produtos que só teriam importância para o comércio da metrópole c que eram, evidentemente, lucrativos.

MARIA LUISA - Os movimentos ecológicos dos países industrializados não correm o risco de se perderem em discussóes sobre as soluçōes técnicas em detrimento das soluçōes sócio-politicas?

WARREN DEAN - Essa forma de ativismo é a mais estratégica. Eu não privilcgiaria nenhum tipo de ativismo. Acho, porém, que o pacifismo está voltado também para uma questão imediata, pois a $3^{2}$ Guerra Mundial poderia terminar tudo nos próximos 15 minutos. As nossas preocupaçōes conservacionistas tentam resolver este confronto entre os dois tipos de ativismo. Apesar das tendências dife- 
rentes no movimento por causa das várias opiniōes, os conservacionistas privilegiam um desenvolvimento que seja capaz de continuar por um horizontc cronológico prolongado. Nāo há, necessariamentc, um conflito entre essas duas problemáticas.

MARIA LUISA - Há uma fronteira entre o norte e o sul. Como poderia haver uma harmonia mundial, sem hegemonia na ecologia?

WARREN DEAN - A ecologia como ciência está no mundo inteiro e as relaçōes naturais estão igualmente em todos os países. Trata-se de um fato: o oxigênio existe aqui e lá, o que faz com que todos participem das conseqüências de sua poluiçāo. Como a problemática ecológica está avançando sobre todos os países do mundo, os povos irāo reagir, o que implicará em um certo grau de intercâmbio de informações, de opiniōes, como cu mesmo estou fazendo agora. No entanto, reconheço o que você está dizendo; reconheço que este é um velho problema de todos os movimentos culturais e até científicos do Brasil.

MARIA LUISA - A questāo do oxigênio é universal, assim como a da preservaçấo do meio ambiente. A problemática da exploração e do uso dos recursos é que amplia, essencialmente, as diferenças entre os países industrializados e os subdesenvolvidos. Gostaria que o Sr. falasse sobre estas diferenças.

WARREN DEAN - Você está abrindo a discussão para outras coisas. Trata-se de um retorno a uma problemática que não tem muito a ver com esse assunto. É evidente que a sua situação vai piorar à medida que o desenvolvimento significar um aumento das exportaçōes de matérias-primas rapidamente esgotáveis. Para este caso, a problemática conservacionista mostra que há outras saídas mais racionais e melhores para a sua sociedade.
MARIA LUISA - Qual a concepção de uma nova cultura mundial para os movimentos ecológicos?

WARREN DEAN - Os ccologistas cstão levantando a seguinte problemática: pela forma como o desenvolvimento está sendo processado no mundo afinal, os economistas estáo defendendo a teoria do crescimento de $2 \%$ a $3 \%$ por ano em todos os países - o futuro se apresentaria com um horizonte muito estreito, pois em uma ou duas gerações, caminharíamos para um colapso. Ao menos, essa é uma das previsōes. O conservacionista está propondo uma coisa simples: uma sociedade talvez diferente, mas que seja viável, pelo menos, pelo tempo correspondente ao número de geraçōes já vividas pela raça humana. É simplesmente a idéia de estabilidade, de um desenvolvimento que leve em consideração a necessidade de um futuro para os nossos filhos e netos.

MARIA LUISA - Como os movimentos ecológicos influenciam nas políticas governamentais, no sentido de propor a racionalizaçã்o na exploraçāo dos recursos naturais, visando o progresso material, sem dissociá-los das políticas sociais?

WARREN DEAN - Eu recomendaria a você a leitura do economista inglês $\mathrm{E}$. J. Mishan. O ponto central das teorias dele é que, em uma sociedade na qual a riqueza é muito concentrada, todo o poder de decisāo sobre o meio ambiente vem, exatamente, dos proprictários. Esses, dispōem de meios para destruir o meio ambiente e o resto da sociedade precisa agüentar. Não é justo, portanto, pensar que os conservacionistas não estāo levando em conta esses fatos que sāo gritantes. Mais ainda, quando se considera a situaçāo em que se encontram os conservacionistas neste país, como em todos os outros, os quais precisam andar esmolando soluçōes de 
pessoas que têm o poder para resolver essas questöes. Supor, portanto, que os conservacionistas sāo inocentes em questōes políticas ou que eles estão tentando evitar um confronto com a realidade de uma sociedade desigual e injusta, é uma bobagem.

MARIA LUISA - Como aproximar a História e a Política na temática ecológica?

WARREN DEAN - Quando os historiadores tentam aplicar a problemática ccológica ao passado, cles têm $\mathrm{cm}$ mente um programa social e político. Eles tentam mostrar às pessoas que a História pode ser relevante de uma maneira diferente; mostrar às pessoas que vivem no presentc o que foi a escravidāo, significa mostrar uma sociedade na qual o tra* balho foi feito na base da violência e da força. A História, nesse sentido, pode dar liçōes. Os historiadores que trabalham sobre a problemática da escravidāo têm, evidentemente, uma idćia de uma sociedade que pode ser melhor. Os historiadores que se interessam sobre o problema do relacionamento do homem como o meio ambiente estão tentando mostrar nāo só as liçōes do passado, mas também indicar situaçōes, como por exemplo, a dos índios do Novo Mundo que tinham um relacionamento mais cstável com o meio ambiente. Há várias maneiras de se ter uma perspectiva, um programa para uma sociedade futura mais racional, mais justa, ao se aplicar a Ecologia à História.

MARIA LUISA - Qual a relação entre ecologia e $a$ violência?

WARREN DEAN - Eu prefiro enfatizar a ligação provável entre a dominação da natureza e a dominaçāo do homem pelo homem. Willian Leiss, autor de The Domination of Nature, remonta, $\mathrm{cm}$ seu livro, à Inglaterra dos anos de 1600 , quando se formulava um programa nacional. Entre as pessoas importantes que participavam desse projeto, encontrava-sc Francis Bacon, cujas pregaçôes em favor de um Estado-Nação forte cnfatizavam a necessidade de se dominar a natureza também. Qucr dizer, a consciência de que a natureza era mesmo algo para scr dominada pelo homem tem origem no paradigma de uma sociedade hierarquizada, exatamente como os animais e a própria natureza. Não há, cxatamente, uma idćia de violência, mas de dominação.

MARIA LUISA - Como o Sr. se interessou pelos estudos latino-americanos e, em particular, pelo Brasil?

WARREN DEAN - Faz tanto tempo que é difícil lembrar. Vivi muitos anos $\mathrm{cm}$ Miami; sou uma pessoa que viveu scmpre em um meio de latino-americanos. Cheguei a conhecer brasileiros na minha faculdade, uma vez que estava pensando em estudar América Latina. Na época, estava interessado $\mathrm{cm}$ fazer História de Cuba, apesar de saber que, ao transmitir a verdade, meus trabalhos poderiam nāo ser publicados. Estava fascinado com a Revoluçāo Cubana - queria assistir, participar - mas, infelizmente, quem chegasse a Cuba com um passaporte americano, dificilmente poderia fazer pesquisa. Em 1963, Cclso Furtado anunciava para todo o mundo que o Brasil estava numa fase de pré-revolução. Achei, cntāo, que seria interessante vir para o sul do continente e assim... 